\title{
Assessing the impact of dietary habits on health-related quality of life requires contextual measurement tools
}

\author{
Cristina Ruano-Rodríguez ${ }^{1,2 *}$, Lluis Serra-Majem ${ }^{1,2}$ and Dominique Dubois ${ }^{3}$ \\ ${ }^{1}$ Nutrition Research Group, Research Institute of Biomedical and Health Sciences, University of Las Palmas de Gran Canaria, \\ Las Palmas de Gran Canaria, Spain, ${ }^{2}$ Ciber Fisiopatología Obesidad y Nutrición, Instituto de Salud Carlos III, Madrid, Spain, \\ ${ }^{3}$ Pharmed, Université Libre de Bruxelles, Brussels, Belgium
}

OPEN ACCESS

Edited by:

Sam Salek,

Institute for Medicines Development,

Reviewed by:

Andrew Eggleston,

Medtronic, Australia

Gerfried K. H. Nell,

Nell Pharma Connect Ltd., Austria

*Correspondence:

Cristina Ruano-Rodríguez, Nutrition Research Group, Research

Institute of Biomedical and Health Sciences, University of Las Palmas

de Gran Canaria, P.O. Box 550, 35080 Las Palmas de Gran Canaria,

Spain

cruano@proyinves.ulpgc.es

Specialty section:

This article was submitted to

Pharmaceutical Medicine and

Outcomes Research,

a section of the journal

Frontiers in Pharmacology

Received: 06 March 2015

Accepted: 23 April 2015

Published: 08 May 2015

Citation:

Ruano-Rodríguez C, Serra-Majem L and Dubois $D$ (2015) Assessing the impact of dietary habits on health-related quality of life requires

contextual measurement tools.

Front. Pharmacol. 6:101.

doi: 10.3389/fphar.2015.00101
The increase of non-communicable diseases at all ages has fostered the general concern for sustaining population health worldwide. Unhealthy lifestyles and dietary habits impacting physical and psycho-social health are well known risk factors for developing life threatening diseases. Identifying the determinants of quality of life is an important task from a Public Health perspective. Consumer-Reported Outcome measures of healthrelated quality of life (HRQoL) are becoming increasingly necessary and relevant in the field of nutrition. However, quality of life questionnaires are seldom used in the nutrition field. We conducted a scientific literature search to find out the questionnaires used to determine the association between dietary habits and quality of life. A total of 13 studies were eligible for inclusion. Across these studies the short form-36, a generic (non-disease specific) HRQoL measurement instrument was the most widely used. However, generic measures may have limited content validity in the context of dietary habits interventions. We recommend additional contextual diet-specific HRQoL measures are also needed for evaluating the impact of diet habits on daily life functioning and well-being.

Keywords: dietary habits, quality of life, health outcome measures, general population, review

\section{Introduction}

Although life expectancy has increased notably in the last years, non-communicable diseases at all ages are increasingly threatening the general population health globally. As people are living longer, policies and programs that enact "active aging" are a necessity. Measuring health-related quality of life (HRQoL) is related to the subjective perception of individuals' health and well-being in relation to its social and cultural environment (Testa and Simonson, 1996). Several factors are well-known determinants of HRQoL (Corica et al., 2008; Guitérrez-Bedmar et al., 2009; Serrano-Aguilar et al., 2009). Diet, together with other aspects of daily life such as physical activity and the relation with the environment, plays a crucial role in our state of physical and mental health.

Self-perceived health status is a simple but effective indicator of overall health status and a useful tool to inform about the care needs and the organization of prevention programs (Guyatt et al., 2007). HRQoL questionnaires are an efficient way of gathering data about people's daily functioning and psycho-social well-being. Also, health status measures have been shown to be a powerful predictor for chronic diseases and mortality over the long term in clinical practice (Wannamethee and Shapher, 1991). 


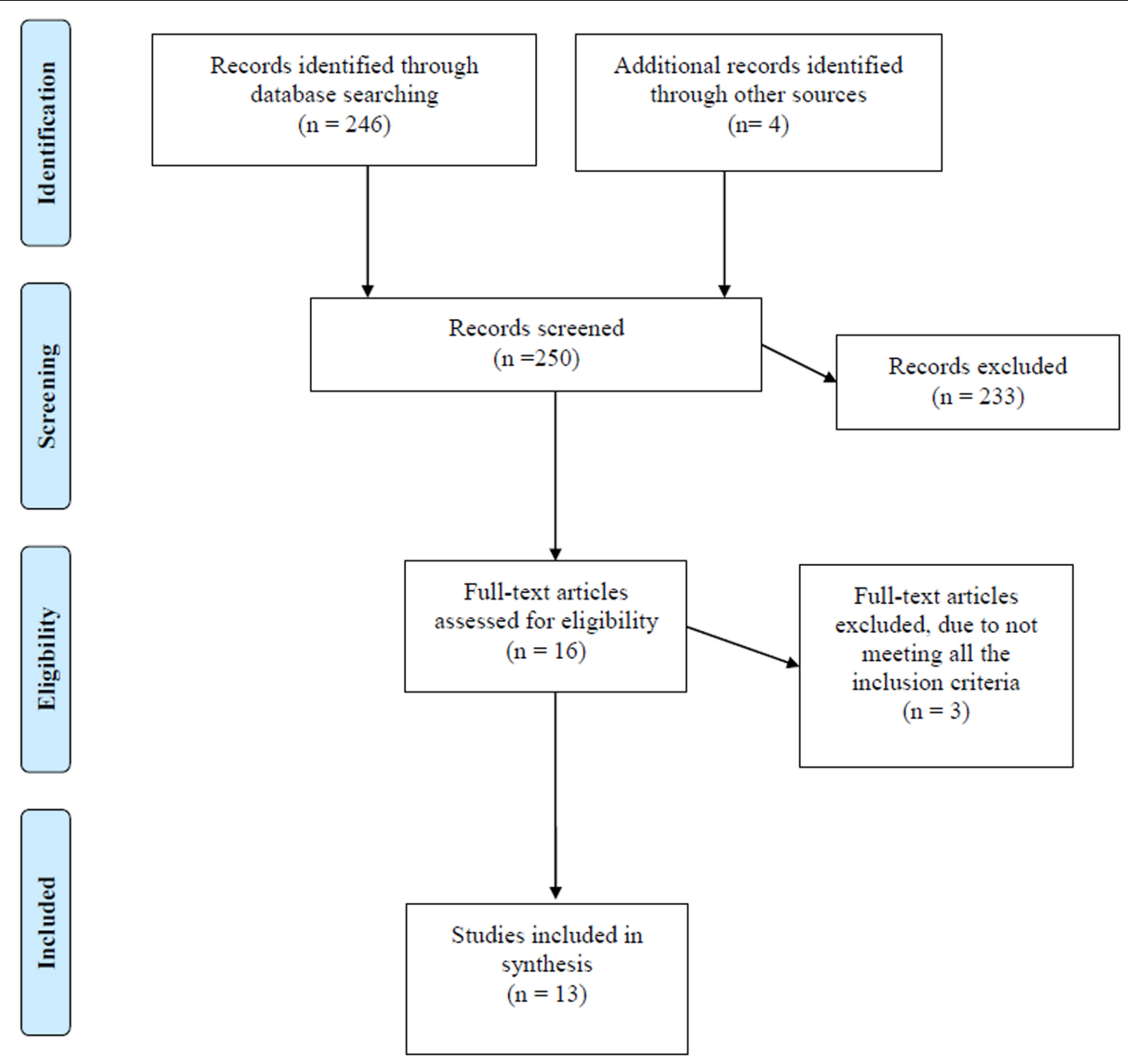

FIGURE 1 | Flow diagram of the review process.

It is now well established that nutrition influences outcomes in patient populations (Barr and Schumacher, 2003a,b), but few studies have assessed the relationship between HRQoL and dietary habits in the general population. Among them, the most used instrument to assess quality of life is the short form-36 (SF-36) Health Survey. However, generic health status measures may have limited content validity in the context of dietary habits interventions. So, our aim was to conduct a review to find out in the scientific literature the questionnaires used to determine the association between dietary habits and quality of life.

\section{Materials and Methods}

The literature search was conducted in Medline, using combinations of the following terms: "diet," "quality of life," and "questionnaires," including MESH-terms. In total 246 articles were selected.

The studies were evaluated applying the following inclusion criteria: (a) studies conducted exclusively in the general population (b) human studies (c) studies written in English (d) studies which used a validated assessment method and (e) studies published in the last 10 years.

After initial review of titles and abstracts, 12 articles appeared to be potentially relevant, and we attempted to obtain them in full-text version. The literature lists in the selected papers were checked. We selected by handsearching four studies from this literature that met the inclusion criteria. Of these 16 potentially eligible articles, three were excluded because they did not meet all eligibility criteria. Finally 13 articles were included in this study (Figure 1).

\section{Results}

The descriptive characteristics of the articles selected are reported in Table 1. From the 13 studies, six were cross-sectional, two randomized clinical trials, six cohort studies, and two validation studies of nutrition-specific tools for HRQoL assessment. The study samples included mostly adult populations except Costarelli et al. (2013) and Wu et al. (2012), which were conducted in young populations (10-16 years old).

The majority of the studies used the SF-36 for assessing quality of life. The exceptions were the two studies conducted in adolescent populations: one study conducted by Costarelli used a specific version of a generic questionnaire for young people: EQ5D-Y (youth), and the other study (Wu et al., 2012) used the KIDSCREEN-27 questionnaire, an instrument to assess subjective health and well-being applicable for healthy and chronically ill children and adolescents aged from 8 to 18 years. Two other 
TABLE 1 | Characteristics of included studies $(n=13)$.

\begin{tabular}{|c|c|c|c|c|c|}
\hline Authors & Study & Design & Country & $\begin{array}{l}\text { Sample characteristics (group size, } \\
n \text {; age, years; gender) }\end{array}$ & $\begin{array}{l}\text { Quality of life } \\
\text { instrument used }\end{array}$ \\
\hline $\begin{array}{l}\text { Duncan et al. } \\
\text { (2014) }\end{array}$ & 10,000 Steps cohort & Cross-sectional & Australia & $n=10,478 ; \geq 18$ years; $70.5 \%$ women & $\begin{array}{l}\text { CDC Healthy Days } \\
\text { Instrument }\end{array}$ \\
\hline $\begin{array}{l}\text { Berendsen et al. } \\
\text { (2013) }\end{array}$ & NU-Age project & RCT & $\begin{array}{l}\text { European } \\
\text { Consortium }\end{array}$ & $n=1,250 ; 65-80$ years & SF-36 \\
\hline Ruano et al. (2013) & SUN project & Cohort & Spain & $n=11,128 ;>21$ years & SF-36 \\
\hline $\begin{array}{l}\text { Germain et al. } \\
(2013)\end{array}$ & SU.VI.MAX trial & Cohort & France & $n=3,005 ; 45-65$ years; $67.7 \%$ women & SF-36 \\
\hline Uritani et al. (2013) & & $\mathrm{RCT}$ & Japan & $n=114 ;$ women $40-74$ years & SF-36 \\
\hline $\begin{array}{l}\text { Costarelli et al. } \\
(2013)\end{array}$ & & Cross-sectional & Greece & $n=359 ; 13-16$ years & KIDSCREEN-27 \\
\hline $\begin{array}{l}\text { Henríquez Sánchez } \\
\text { et al. (2012) }\end{array}$ & SUN project & Cohort & Spain & $n=11,015 ;>21$ years & SF-36 \\
\hline Wu et al. (2012) & REAL Kids Alberta & Cross-sectional & Alberta (Canada) & $n=3421 ; 10-11$ years & EQ-5D-Y (youth) \\
\hline Muñoz et al. (2009) & & Cross-sectional & Girona (Spain) & $n=7,145 ; 25-74$ years; 3,697 women & SF-12 \\
\hline $\begin{array}{l}\text { Bonaccio et al. } \\
\text { (2013) }\end{array}$ & Moli-Sani project & Cross-sectional & Italy & $n=16,937 ; \geq 35$ years; $48.4 \%$ men & SF-36 \\
\hline Kimura et al. (2009) & & Cross-sectional & Japan & $n=689 ; \geq 65$ years; 401 women & QOL \\
\hline $\begin{array}{l}\text { Schünemann et al. } \\
\text { (2010) }\end{array}$ & & Validation study & Italy & $n=128 ; 20-65$ years; 35.9\% men & QUALCIBO \\
\hline $\begin{array}{l}\text { Guyonnet et al. } \\
\text { (2008) }\end{array}$ & & Validation study & France & $n=197 ; 20-65$ years; 64\% women & FBA \\
\hline
\end{tabular}

studies used a specific tool for assessing HRQoL: the CDC Healthy Days instrument in the study conducted by Duncan et al. (2014), and the quantitative HRQoL for old people living in the community, in the study conducted by Kimura et al. (2009).

We identified only two nutrition-specific instruments: the Food Benefits Assessment (FBA; Guyonnet et al., 2008) and the Qualcibo questionnaire (Schünemann et al., 2010).

\section{Discussion}

This review, designed to find out which instrument was mostly used to determine quality of life in relation to dietary habits, revealed that there are few studies that have been conducted to determine if the adherence to a specific dietary pattern could have a positive or negative influence on HRQoL in the general population. The large majority of studies regarding nutrition and quality of life have been performed in a clinical setting (Katcher et al., 2010; Cash et al., 2012) and the SF-36 was the most widely used measurement tool in this setting (Imayama et al., 2011; Villareal et al., 2011; Xu et al., 2012).

To our knowledge only two specific instruments have been developed to determine specifically the impact of diet on HRQoL in the general population, but we did not find any publication regarding their practical application, possibly because their validation is still in progress. Our results are in concordance with a recent systematic review conducted by Carson et al. (2014) regarding the effects of dietary interventions to promote weight loss on quality of life. One of the questionnaires is The FBA developed by Guyonnet et al. (2008), this questionnaire contains 41 questions that measure the impact of daily diet on eight dimensions of HRQoL, as perceived by subjects: vitality (10 items), digestive comfort (nine items), disease prevention (six items), well-being (six items), aesthetics (five items), physical appearance (three), snacking (two items), and pleasure (two items). The 41 items of the questionnaire showed good internal consistency reliability (Cronbach's $\alpha=0.79$ to 0.91 ) and reproducibility. Intraclass correlation coefficient (ICC) scores exceeded the 0.70 threshold for all dimensions. When comparing FBA dimensions with SF36 to determine the concurrent validity of the questionnaire, the Spearman correlation coefficients ranged from 0.02 (snacking) to 0.83 (well-being). No floor or ceiling effects were detected. The FBA's sensitivity over time needs to be determined in further long-term studies, as acknowledged by the authors.

The other nutrition-specific instrument most recently developed is the Qualcibo questionnaire initially validated for Italian population by Schünemann et al. (2010). It contains 29 items across five domains to assess quality of life related to nutrition and other aspects of food intake: Healthy lifestyle ( $n=10$ items), symptoms ( $n=6$ items), sensations ( $n=6$ items), social and role function ( $n=4$ items), and taste ( $n=3$ items). The Qualcibo questionnaire still needs further longitudinal construct validity and responsiveness assessment, since the authors only performed cross-sectional validation.

The following studies illustrate that generic, disease-specific and nutrition-specific questionnaires can provide valuable insights on the impact on general quality of life, as long as the measurement tool is applicable to the context and the research question of interest. 
The CDC's Healthy Days instrument was used in a large cross-sectional on-line survey in members of the web-based 10,000 Steps project physical activity promotion initiative (www. 10000steps.org.au). The study objective was to evaluate the HRQoL impact of several lifestyle behaviors, including diet (Duncan et al., 2014). The assessment of dietary behaviors included consumption of daily fruit and vegetables, soft drinks and fast foods. Poor dietary behaviors, as well as smoking, lower levels of physical activity, higher sitting time, and poor sleep behaviors, were shown to be associated with poor self-rated health and frequent unhealthy days.

In the 2001-2004 National Health and Nutrition Examination Survey, the Healthy Days questions were used to compare the impact of hypertension on general HRQoL in participants with and without hypertension (Hayes et al., 2008). A higher number of unhealthy days were reported by the respondents with hypertension.

The choice of the type of questionnaire should be based on the specific context and purpose of the study. For example, if the purpose is to compare the health status of healthy lifestyle and different diseases, the non-disease specific SF-36 is recommendable. If the purpose is to generate data that will allow to determine utilities for calculating Quality Adjusted Life Years, generic preferencebased measures are recommended (e.g., EQ-5D, SF-6D, Health Utility Index; Walters and Brazier, 2003; Cruz et al., 2011).

To deepen the understanding of the impact of healthy as well as unhealthy dietary habits, we propose to start with reviewing the appropriateness of the few available nutrition-specific questionnaires for the specific purpose of your study, and search for other available measures to fill the potential contextual gaps, e.g., for measuring symptoms, (dis)satisfaction with (un)healthy diet intervention, or sleep quality.

Our study has some limitations. We limited our detailed review to those articles available in open access, so we could have missed other HRQoL instruments not available in a free format. We also

\section{References}

Barr, J., and Schumacher, G. (2003a). Using focus groups to determine what constitutes quality of life in clients receiving medical nutrition therapy: first steps in the development of a nutrition quality-of-life survey. J. Am. Diet. Assoc. 103, 844-851. doi: 10.1016/S0002-8223(03)00385-7

Barr, J. T., and Schumacher, G. E. (2003b). The need for a nutrition-related qualityof-life measure. J. Am. Diet. Assoc. 103, 177-180. doi: 10.1053/jada.2003.50058

Berendsen, A., Santoro, A., Pini, E., Cevenini, E., Ostan, R., Pietruszka, B., et al. (2013). A parallel randomized trial on the effect of a healthful diet on inflammageing and its consequences in European elderly people: design of the NUAGE dietary intervention study. Mech. Ageing Dev. 134, 523-530. doi: 10.1016/ j.mad.2013.10.002

Bonaccio, M., Di Castelnuovo, A., Bonanni, A., Costanzo, S., De Lucia, F., Pounis, G., et al. (2013). Adherence to a Mediterranean diet is associated with a better health-related quality of life: a possible role of high dietary antioxidant content. BMJ Open 3, e003003. doi: 10.1136/bmjopen-2013-003003

Carson, T. L., Hidalgo, B., Ard, J. D., and Affuso, O. (2014). Dietary interventions and quality of life: a systematic review of the literature. J. Nutr. Educ. Behav. 46, 90-101. doi: 10.1016/j.jneb.2013.09.005

Cash, S. W., Beresford, S. A., Henderson, J. A., Mctiernan, A., Xiao, L., Wang, C. Y., et al. (2012). Dietary and physical activity behaviours related to obesity-specific quality of life and work productivity: baseline results from a worksite trial. $\mathrm{Br}$. J. Nutr. 108, 1134-1142. doi: 10.1017/S0007114511006258 limited our search to articles published in the last 10 years. We excluded articles not conducted in the general population. Given the ambiguity of the term general population, this may have led us to skip some studies in our search.

\section{Conclusion}

From a Public Health perspective it is an important but challenging task to measure the HRQoL effects of food habits within the general population. The choice of type of questionnaires depends on the specific research question to be answered. To our knowledge only two nutrition-specific instruments have been developed to determine the impact of nutrition in the general population. Additional measurement tools are needed to explore in more depth the associations between dietary habits and their impact on population health outcomes.

\section{Author Contributions}

$\mathrm{CR}$ and DD developed the study design and drafted the manuscript. LS provided guidance on analysis and data interpretation. All authors provided final approval of the manuscript.

\section{Acknowledgments}

The authors are grateful to Ms. Itandehui Castro and Dr. Mariela Nissensohn for their assistance in the search methodology. The authors also gratefully acknowledge the Health Technology Assessment international (HTAi) society for their financial support in the payment of the article publishing fee and for supporting the Research Topic initiative by the Interest Sub-Group on the Impact of Public Health interventions-special focus on Nutrition-on Health Outcomes Research and Measurement (INPHORM).

Corica, F., Corsonello, A., Apolone, G., Mannucci, E., Lucchetti, M., Bonfiglio, C., et al. (2008). Metabolic syndrome, psychological status and quality of life in obesity: the QUOVADIS Study. Int. J. Obes. (Lond.) 32, 185-191. doi: 10.1038/ sj.ijo.0803687

Costarelli, V., Koretsi, E., and Georgitsogianni, E. (2013). Health-related quality of life of Greek adolescents: the role of the Mediterranean diet. Qual. Life Res. 22, 951-956. doi: 10.1007/s11136-012-0219-2

Cruz, L. N., Camey, S. A., Hoffmann, J. F., Rowen, D., Brazier, J. E., Fleck, M. P., et al. (2011). Estimating the SF-6D value set for a population-based sample of Brazilians. Value Health 14, S108-S114. doi: 10.1016/j.jval.2011.05. 012

Duncan, M. J., Kline, C. E., Vandelanotte, C., Sargent, C., Rogers, N. L., and Di Milia, L. (2014). Cross-sectional associations between multiple lifestyle behaviors and health-related quality of life in the 10,000 Steps cohort. PLoS ONE 9:e94184. doi: 10.1371/journal.pone.0094184

Germain, L., Latarche, C., Kesse-Guyot, E., Galan, P., Hercberg, S., and Briançon, S. (2013). Does compliance with nutrition guidelines lead to healthy aging? A quality-of-life approach. J. Acad. Nutr. Diet. 113, 228-240.e2. doi: 10.1016/ j.jand.2012.10.015

Guitérrez-Bedmar, M., Seguí-Gómez, M., Gómez-Gracia, E., Bes-Rastrollo, M., and Martínez-González, M. A. (2009). Smoking status, changes in smoking status and health-related quality of life: findings from the SUN ("Seguimiento Universidad de Navarra”) cohort. Int. J. Environ. Res. Public Health 6, 310-320. doi: 10.3390/ijerph6010310 
Guyatt, G. H., Ferrans, C. E., Halyard, M. Y., Revicki, D. A., Symonds, T. L., Varricchio, C. G., et al. (2007). Exploration of the value of health-related qualityof-life information from clinical research and into clinical practice. Mayo Clin. Proc. 82, 1229-1239. doi: 10.4065/82.10.1229

Guyonnet, D., Chassany, O., Picard, C., Guillemin, I., Meunier, J., Seignobos, E., et al. (2008). Perceived subject outcomes and impact on health-related quality of life associated with diet using the new Food Benefits Assessment (FBA) questionnaire: development and psychometric validation. Public Health Nutr. 11, 1163-1172. doi: 10.1017/S1368980008001729

Hayes, D. K., Denny, C. H., Keenan, N. L., Croft, J. B., and Greenlund, K. J. (2008). Health-related quality of life and hypertension status, awareness, treatment, and control: National Health and Nutrition Examination Survey, 2001-2004. J. Hypertens. 26, 641-647. doi: 10.1097/HJH.0b013e3282f3eb50

Henríquez Sánchez, P., Ruano, C., De Irala, J., Ruiz-Canela, M., Martínez-González, M. A., and Sánchez-Villegas, A. (2012). Adherence to the Mediterranean diet and quality of life in the SUN Project. Eur. J. Clin. Nutr. 66, 360-368. doi: 10.1038/ejen.2011.146

Imayama, I., Alfano, C. M., Kong, A., Foster-Schubert, K. E., Bain, C. E., Xiao, L., et al. (2011). Dietary weight loss and exercise interventions effects on quality of life in overweight/obese postmenopausal women: a randomized controlled trial. Int. J. Behav. Nutr. Phys. Act. 8, 118. doi: 10.1186/1479-5868-8118

Katcher, H. I., Ferdowsian, H. R., Hoover, V. J., Cohen, J. L., and Barnard, N. D. (2010). A worksite vegan nutrition program is well-accepted and improves health-related quality of life and work productivity. Ann. Nutr. Metab. 56, 245-252. doi: 10.1159/000288281

Kimura, Y., Wada, T., Ishine, M., Ishimoto, Y., Kasahara, Y., Konno, A., et al. (2009). Food diversity is closely associated with activities of daily living, depression, and quality of life in community-dwelling elderly people. J. Am. Geriatr. Soc. 57, 922-924. doi: 10.1111/j.1532-5415.2009.02235.x

Muñoz, M. A., Fíto, M., Marrugat, J., Covas, M. I., Schröder, H., and Investigators, R. A. H. (2009). Adherence to the Mediterranean diet is associated with better mental and physical health. Br. J. Nutr. 101, 1821-1827. doi: 10.1017/S0007114508143598

Ruano, C., Henriquez, P., Martínez-González, M., Bes-Rastrollo, M., Ruiz-Canela, M., and Sánchez-Villegas, A. (2013). Empirically derived dietary patterns and health-related quality of life in the SUN project. PLoS ONE 8:e61490. doi: 10.1371/journal.pone.0061490

Schünemann, H. J., Sperati, F., Barba, M., Santesso, N., Melegari, C., Akl, E. A., et al. (2010). An instrument to assess quality of life in relation to nutrition: item generation, item reduction and initial validation. Health Qual. Life Outcomes 8, 26. doi: 10.1186/1477-7525-8-26

Serrano-Aguilar, P., Muñoz-Navarro, S. R., Ramallo-Fariña, Y., and Trujillo-Martín, M. M. (2009). Obesity and health related quality of life in the general adult population of the Canary Islands. Qual. Life Res. 18, 171-177. doi: 10.1007/s11136008-9427-1

Testa, M. A., and Simonson, D. C. (1996). Assessment of quality-of-life outcomes. N. Engl. J. Med. 334, 835-840. doi: 10.1056/NEJM199603283341306

Uritani, D., Matsumoto, D., Asano, Y., Yoshizaki, K., Nishida, Y., and Shima, M. (2013). Effects of regular exercise and nutritional guidance on body composition, blood pressure, muscle strength and health-related quality of life in community-dwelling Japanese women. Obes. Res. Clin. Pract. 7, e155-e163. doi: 10.1016/j.orcp.2011.10.005

Villareal, D. T., Chode, S., Parimi, N., Sinacore, D. R., Hilton, T., ArmamentoVillareal, R., et al. (2011). Weight loss, exercise, or both and physical function in obese older adults. N. Engl. J. Med. 364, 1218-1229. doi: 10.1056/NEJMoa1008234

Walters, S. J., and Brazier, J. E. (2003). What is the relationship between the minimally important difference and health state utility values? The case of the SF-6D. Health Qual. Life Outcomes 1, 4. doi: 10.1186/1477-7525-1-4

Wannamethee, G., and Shapher, A. G. (1991). Self-assessment of health status and morbidity and mortality in middle-aged British men. Int. J. Epidemiol. 2, 239-245. doi: 10.1093/ije/20.1.239

Wu, X. Y., Ohinmaa, A., and Veugelers, P. J. (2012). Diet quality, physical activity, body weight and health-related quality of life among grade 5 students in Canada. Public Health Nutr. 15, 75-81. doi: 10.1017/S1368980011002412

Xu, J., Qiu, J., Chen, J., Zou, L., Feng, L., Lu, Y., et al. (2012). Lifestyle and healthrelated quality of life: a cross-sectional study among civil servants in China. BMC Public Health 12:330. doi: 10.1186/1471-2458-12-330

Conflict of Interest Statement: The authors declare that the research was conducted in the absence of any commercial or financial relationships that could be construed as a potential conflict of interest.

Copyright (C) 2015 Ruano-Rodríguez, Serra-Majem and Dubois. This is an open-access article distributed under the terms of the Creative Commons Attribution License (CC $B Y)$. The use, distribution or reproduction in other forums is permitted, provided the original author(s) or licensor are credited and that the original publication in this journal is cited, in accordance with accepted academic practice. No use, distribution or reproduction is permitted which does not comply with these terms. 